\title{
Evaluation of automated in-line precision dairy farming technology implementation in three dairy farms in Italy
}

\author{
Maria CARIA, Giuseppe TODDE (凶), Antonio PAZZONA
}

Department of Agricultural Sciences, University of Sassari, 07100 Sassari, Italy

\begin{abstract}
In recent decades, dairy farms have been exposed to wide variation in profit levels due to a considerable variability of milk price, and energy and feed costs. Consequently, it is necessary for the dairy industry to improve efficiency and productivity by adopting innovative technologies. The automated inparlour milk analysis and separation is mainly useful to produce low or high quality milk and to monitor the animal health status. Milk with high levels of protein and fat contents may reduce the intensity of standardization during cheesemaking process, reducing production costs. The study aimed to evaluate the efficiency of real-time milk separation during milking and the performance of the milking machine after implementation of AfiMilk MCS. In addition, the economic aspects were assessed. The separation of milk required the existing milking parlors to be equipped with an additional milkline to allow channeling milk with low and high coagulation properties into two different cooling tanks. The results showed that the high coagulation milk fraction, compared to the bulk milk, increased in fat (from 18\% to 43\%) and protein (from $3 \%$ to $7 \%$ ) concentration. The technology tested has given promising results showing reliability and efficiency in milk separation in real time with affordable implementation costs.
\end{abstract}

Keywords cheese yield, infrared analysis, milk quality, real-time measurement, sensor

\section{Introduction}

In recent decades, the dairy industry manages production according to high quantitative and qualitative criteria, placing modern dairy farming within a highly competitive national and international supply chain. However, dairy farms have been exposed to wide variation in profit levels

Received October 18, 2018; accepted January 15, 2019

Correspondence: gtodde@uniss.it due to considerable variability of milk price, and energy and feed costs ${ }^{[1-4]}$. For these reasons, it is necessary that the dairy industry improves competitiveness by adopting innovative production processes and improving animal welfare. Improvement and miniaturization of sensors along with continuing costs reduction encourage the implementation of new technologies in dairy farms, allowing increases in their efficiency and productiveness ${ }^{[5-7]}$.

In these terms, the use of a milk analysis system in real time for each individual cow will be a useful way to monitor modern dairy farms ${ }^{[8]}$. This is part of the management system known as Precision Livestock Farming (PLF), which aims to do the right thing at the right time $^{[9]}$ and outlines a new approach to the application of advanced technologies in the livestock sector ${ }^{[0]}$.

Milk composition varies from animal to animal depending on the production stage and many other factors (such as nutrition, physiologic status and health) ${ }^{[11,12]}$. For this reason, different animals and breeds have been selected and diverse dairy products have been refined according to standard requirements ${ }^{[13-15]}$.

The automatic assessment of milk composition is useful for several reasons: (1) to differentiate animals producing low- or high-quality milk ${ }^{[16]}$, (2) to monitor animal health status $^{[17-19]}$, and (3) to perform a real-time separation. In particular, the separation of milk may be a useful way to obtain two products with different quality characteristics, such as nutraceutical cheese-making properties, from the same dairy farm.

Separation of milk during milking procedures is an innovative way to improve the value of milk. AfiMilk MCS is a technology that can be implemented in milking parlors, and allows two different fractions of milk to be obtained based on a near-infrared spectrum light scattering (which does not manipulate, modify, heat or add any ingredients to the milk) ${ }^{[20-22]}$. By channeling the milk into two fractions, according to predetermined qualitative characteristics (e.g., fats, proteins and coagulation properties), the cheese yields can be increased. Thus, cheesemaking plants have the advantage of withdrawing milk 
with specific characteristics closest to those required by the target recipe for cheese production or whole milk for drinking.

In addition, diversification of production also requires a revision of the logistics of the milk collection, which is of considerable importance in the collection and delivery of milk $^{[23,24]}$.

The adoption of PLF technologies can minimize the environmental impact of farms, increase their economic sustainability and improve livestock welfare ${ }^{[25-27]}$. The energy requirements and environmental sustainability of the new method of separation and collection of milk have been calculated through a life cycle assessment approach, and found to provide important energy and environmental benefits along the entire milk supply chain ${ }^{[23]}$.

In this context, the objectives of this study were: (1) to evaluate the milk channeling efficiency of an innovative technology, implemented in milking parlors, for the realtime analysis and separation of milk with different compositions, (2) to evaluate the working performance in these milking parlors, and (3) to estimate the implementation costs of the AfiMilk MCS systems on dairy farms.

\section{Materials and methods}

\subsection{Dairy farms characteristics}

This study was conducted on three commercial dairy farms located in Oristano Province, Sardinia, Italy. The farms specialized in milk production with confinement management and were located in a valley. The specific characteristics of the three dairy farms were: Farm A, land area of 72 ha, 500 head of Italian Holstein $(90 \%)$ and Brown Swiss (10\%) cows, monthly milk production $178400 \mathrm{~kg}, 8+8$ herringbone milking parlor equipped with low-level milkline; Farm B, cropped land area of 85 ha, 600 heads of Holstein cows, monthly milk production of $204000 \mathrm{~kg}$, herringbone milking parlor 15 +15 stalls with low-level milkline; Farm C, land area of 100 ha, 480 heads of Holstein cows, $193100 \mathrm{~kg}$ of milk production per month, $9+9$ stalls in a herringbone milking parlor with low-level milkline.

\subsection{Real time milk separation}

During milking, the milk separation took place in real time for individual cows. This was made possible by the installation of an AfiMilk MCS system (online milk classification service; AfiMilk Ltd., Afikim, Israel) on each farm. The harvested milk is classified in real time during milking and diverted into two different cooling tanks depending on its coagulation properties. One tank received milk suitable for the production of cheese (CF) and the other drinking milk (DF). AfiMilk MCS is basically composed of the AfiLab (an optical in-line milk component analyzer) and an electronic lactometer (AfiMilk MPC). AfiLab is installed between the AfiMilk MPC and the milking point, and measures in real time for every lactometer release the composition of the milk each cow gives. This system activates a valve during milking that diverts and channels the harvested milk into different tanks based on its coagulation properties and other related quality criteria (Fig. 1).

In this study, the AfiMilk MCS was set to separate milk with three different series of separation CF:DF ratios: 40:60, 50:50 and 70:30. From each separation ratio, milk samples were collected from the bulk milk tank and transferred within $1 \mathrm{~h}$ at $4^{\circ} \mathrm{C}$ to the ARAS (Associazione Regionale Allevatori Sardegna) laboratory ${ }^{[28]}$ in Oristano.

Milk classification was optimized through tests performed in the 15 days before the start of the experiments. For each series of separation ratios, the mean values of bulk milk components were recorded.

The milk parameter considered to evaluate the milk separation efficiency were: protein $(\%)$, fat $(\%)$, casein $(\%)$, casein/protein ratio (\%), using Fourier transform infrared spectroscopy (MilkoScan-Foss-Electric, Denmark); Somatic Cell Count $\left(\mathrm{SCC}\right.$; cell $\left.\cdot \mathrm{mL}^{-1}\right)$ using

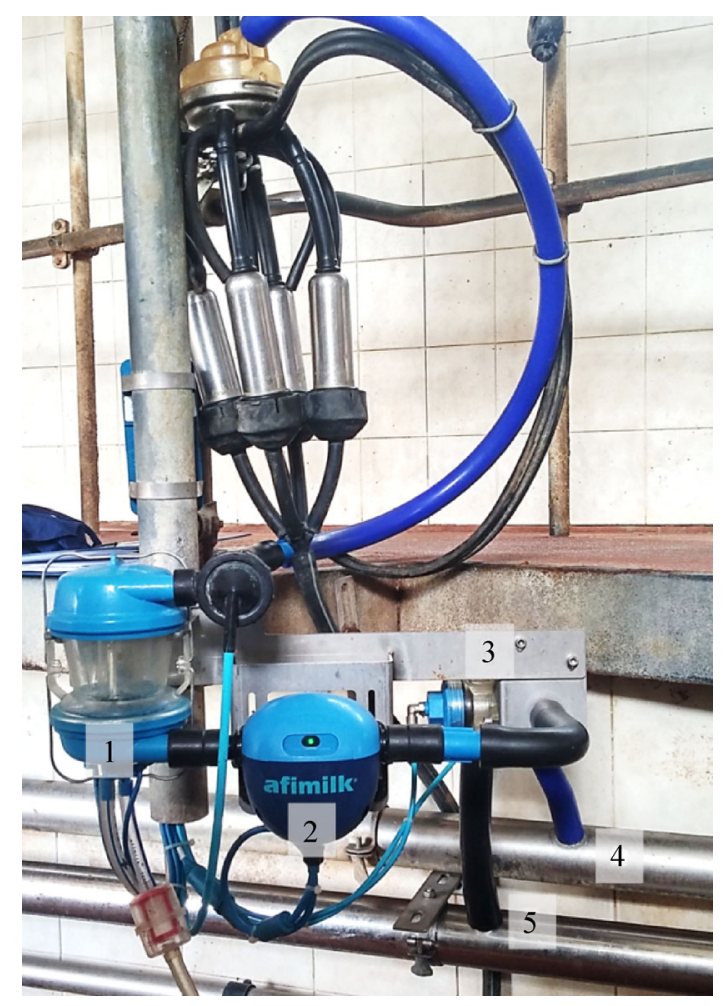

Fig. 1 The AfiLab (2) installed next to the AfiMilk milk meter (1) performs real-time analysis of milk components using spectroscopy in the near infrared. Milk with predefined coagulation properties is separated and channeled using specific valves (3) through two different milklines (4 or 5 ) in a predetermined refrigeration tank. 
an automated flow cytometer (Fossomatic FC-Foss Electric, Denmark); Total Bacterial Count (TBC, colony forming units $\mathrm{CFU} \cdot \mathrm{mL}^{-1}$ ) and amount of milk $(\mathrm{kg})$.

The tests were performed between May and September 2015. The total number of analyses accomplished for each CF:DF were 17 (40:60), 158 (50:50) and 27 (70:30).

Moreover, frequencies, means and standard deviations were calculated for each experiment to characterize the differences between the $\mathrm{CF}$ and DF in each separation ratio. Statistical differences $(P<0.01)$ between the two milk fractions were assessed using the Mann-Whitney test (SPSS Inc., Chicago, IL, USA).

\subsection{Milking machine performance}

The separation of milk in real time with the AfiLab MCS system required the installation of a milk meter, an optical reader and two valves to direct the milk in two different lines. To assess the stability of the operative vacuum pressure during milking, specific mechanical field tests were performed for each milking machine. These tests allowed for several measurements and controls, both with animals in milking (milking-time tests) and with the machine running, but no milking (dry tests). The milkingtime and the dry tests were performed specifically to measure the mean vacuum and vacuum fluctuations in the milkline, in order to evaluate the changes in the configurations of milking parlors.

Experimental data were recorded with an electronic data acquisition system (DAS-M, Star Ecotronics, Milan, Italy) connected to a portable computer. This system was equipped with four channels with a sampling frequency of $1000 \mathrm{~Hz}$ per channel. Pressure sensors operated in the range -100 to $+150 \mathrm{kPa}$ with an accuracy of $\pm 0.25 \mathrm{kPa}$ at a vacuum pressure of $50 \mathrm{kPa}$. Data were acquired in real time and recorded in graphical form with two active pointers making it possible to reconstruct a detailed vacuum trend.

During the dry test, the vacuum fluctuations were recorded while two clusters were progressively opened. Vacuum fluctuations were measured at the same time in both milklines connecting the sensors near the receiver. The vacuum level was recorded for a duration of $120-140 \mathrm{~s}$ to obtain a mean fluctuation value for different situations.

\subsection{Implementation costs}

The economic analysis was addressed for each dairy farm, taking into consideration all the modifications done for the implementation of the AfiMilk MCS system. The engineering and wiring costs were provided directly by the installer, while the farm manager provided the costs related to any structural work required for the implementation of the additional components in the milking parlor.

\section{Results and discussion}

\subsection{Milk separation tests}

The first assessment performed was the amount of milk separated (Table 1). The results showed an acceptable degree of separation for the two milk fractions in all three dairy farms involved.

The system has shown the ability to separate the milk in real time in accordance with the threshold set. Therefore, the separation is not affected by the cutoff level, i.e., when the separation level is strongly unbalanced (e.g., 70:30).

Fat, protein and casein concentrations between $\mathrm{CF}$ and DF were always significantly different across farms and separation ratios.

For all farms, the values of fat and protein in $\mathrm{CF}$ were higher with a separation ratio of 40:60 (CF:DF). In particular, fat concentration ranged from $2.06 \%$ to $2.53 \%$, while the variation in protein concentration was less $(0.23 \%-0.36 \%)$. Compared to bulk milk (CF + DF), each farm showed an increase in the concentrations of fat and protein (Table 2).

On Farm A, the fat and protein concentrations in $\mathrm{CF}$ ranged from $18 \%$ to $43 \%$, and $3 \%$ to $5 \%$, respectively. Farm B showed an increase, compared to the bulk milk, from $23 \%$ to $35 \%$ for the fat and an increase in proteins ranging from $4 \%$ to $7 \%$, while for Farm $\mathrm{C}$ the respective ranges were $20 \%$ to $38 \%$, and from $3 \%$ to $7 \%$. The system can separate $\mathrm{CF}$ with different properties, enabling the cheese making process to yields up to $10 \%-15 \%{ }^{[20-22,29]}$.

On all farms, the highest casein concentrations were always found in CF. Compared to bulk milk, the greatest concentration was 7\% with the 40:60 ratio. Whereas, the lowest was $2 \%-3 \%$ with the $70: 30$ ratio. The casein/ protein ratio showed no differences across the three ratios of separation. In the same way, small increases $(0.1 \%-$ $0.6 \%$ ) were found between CF milk with the bulk milk. Total microbial counts were not significantly different between CF and DF. For all separation ratios, the somatic cell count was higher in CF, particularly in the 40:60 ratio. The statistical analysis performed on SCC showed significantly differences between $\mathrm{CF}$ and DF only in the 50:50 ratio. Although these values were higher in CF milk, the levels obtained in these tests were found to be well below the limit of $400000 \mathrm{cell} \cdot \mathrm{mL}^{-1[30]}$ and did not compromise milk quality. Monitoring the SCC levels in real time for each individual cow, strongly improved the animal welfare of the herd. In turn, this produced an increase in the milk quality produced. Lombardo et al. ${ }^{[31]}$ also evaluated agrochemicals and other environmental contaminants $\left(\mathrm{Ca}, \mathrm{CO}_{2}, \mathrm{NO}_{3}, \mathrm{NH}_{4}\right.$, etc.) in milk, using a selection of specific sensors implemented in the AfiMilk MCS. 


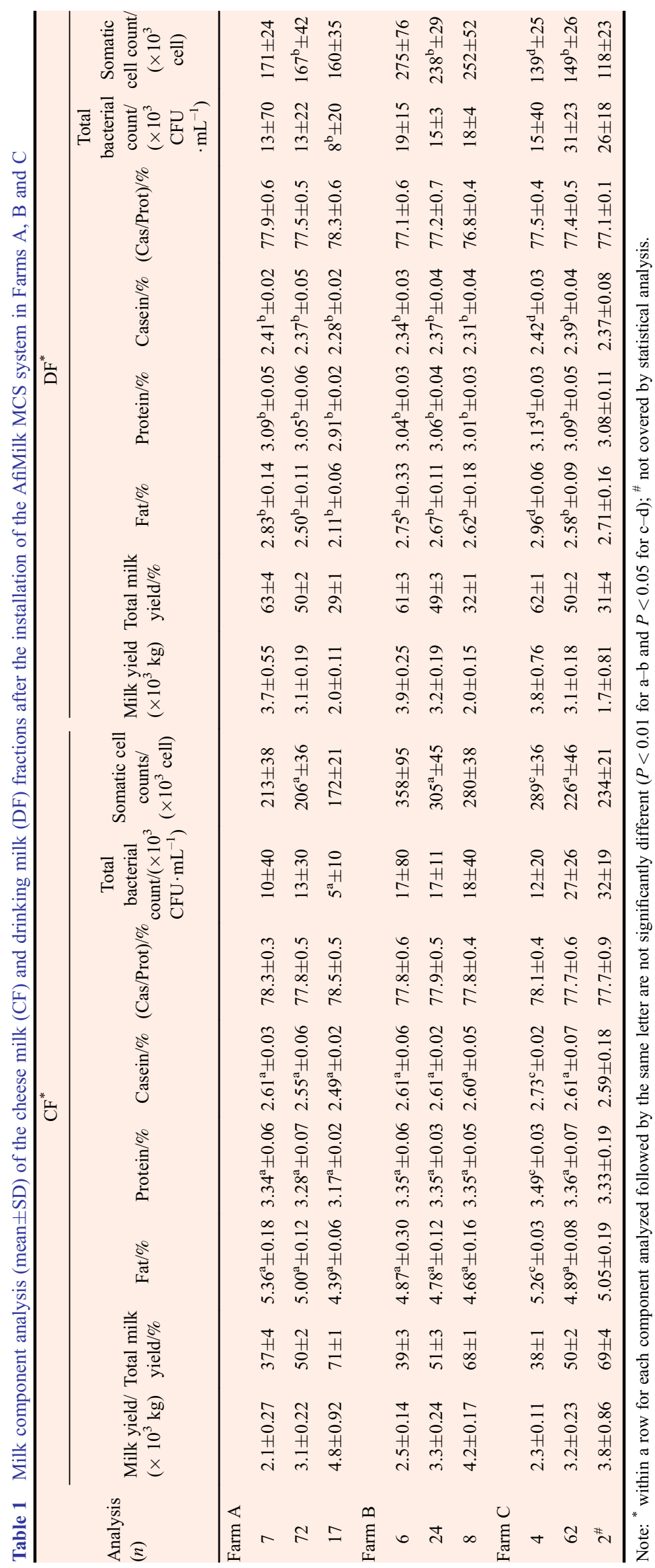


Table 2 Mean components of bulk milk (CF $+\mathrm{DF})$ by farm and separation ratio

\begin{tabular}{lcccccc}
\hline Farm & $\begin{array}{c}\text { Separation } \\
\text { ratio per farm }\end{array}$ & Total milk $/\left(\times 10^{3} \mathrm{~kg}\right)$ & Fat $/ \%$ & Protein/\% & Casein/\% & (Cas/Prot $) / \%$ \\
\hline A & $40: 60$ & $5.8 \pm 0.63$ & $3.75 \pm 0.21$ & $3.18 \pm 0.06$ & $2.48 \pm 0.03$ & $78.1 \pm 0.50$ \\
& $50: 50$ & $6.1 \pm 0.35$ & $3.75 \pm 0.09$ & $3.17 \pm 0.06$ & $2.46 \pm 0.05$ & $77.7 \pm 0.42$ \\
& $70: 30$ & $6.8 \pm 0.11$ & $3.72 \pm 0.05$ & $3.09 \pm 0.01$ & $2.43 \pm 0.02$ & $78.4 \pm 0.40$ \\
B & $40: 60$ & $6.4 \pm 0.14$ & $3.58 \pm 0.25$ & $3.16 \pm 0.03$ & $2.44 \pm 0.03$ & $77.4 \pm 0.57$ \\
& $50: 50$ & $6.4 \pm 0.24$ & $3.74 \pm 0.08$ & $3.21 \pm 0.03$ & $2.49 \pm 0.03$ & $77.6 \pm 0.57$ \\
& $70: 30$ & $6.1 \pm 0.28$ & $3.80 \pm 0.14$ & $3.20 \pm 0.04$ & $2.48 \pm 0.04$ & $77.4 \pm 0.37$ \\
C & $40: 60$ & $6.1 \pm 0.17$ & $3.83 \pm 0.06$ & $3.26 \pm 0.01$ & $2.54 \pm 0.02$ & $77.7 \pm 0.33$ \\
& $50: 50$ & $6.3 \pm 0.32$ & $3.74 \pm 0.07$ & $3.23 \pm 0.06$ & $2.50 \pm 0.05$ & $77.5 \pm 0.50$ \\
& $70: 30$ & $5.5 \pm 0.17$ & $4.21 \pm 0.09$ & $3.23 \pm 0.15$ & $2.51 \pm 0.14$ & $77.5 \pm 0.56$ \\
\hline
\end{tabular}

\subsection{Vacuum stability}

The fluctuation in vacuum pressure in the milkline is a parameter that may be affected by changes in the design and configuration of milking parlors, as well as increasing mechanization and automation levels. To verify that the implementation of the milk separation system did not compromise the stability of the vacuum pressure during milking, specific measurements were made to verify compliance of an installation with the requirements of ISO 5707:2007 $7^{[32,33]}$.

Mechanical tests were performed both during milking and on a milking machine running dry, on each of the farms. The milking-time tests are the most direct indicator of the performance of any milking system ${ }^{[34]}$. At the same time, dry tests are also suitable for field use and permit simulation of different operational incidents (e.g., air admission due to careless operators or liner slip). The values recorded were in all cases lower than the vacuum fluctuation limit of $2 \mathrm{kPa}$ under ISO 5707:2007 as the maximum limit to guarantee an optimal milking (Fig. 2).

The results of milking-time tests are shown in Table 3. The modifications made on the milking systems did not, therefore, compromise the quality of milking in terms of vacuum stability.

\subsection{Cost analysis of AfiMilk MCS system implementation}

The costs of commercial implementation of the systems were also analyzed to provide information for meaningful extension of this innovative technology to the dairy industry. The operators of the dairy farms involved in the study have been interested in a modernization their milking parlor to achieve the objectives of the research. The total cost incurred by each farm has been adjusted according to the size of the milking parlor, the number of milking cows

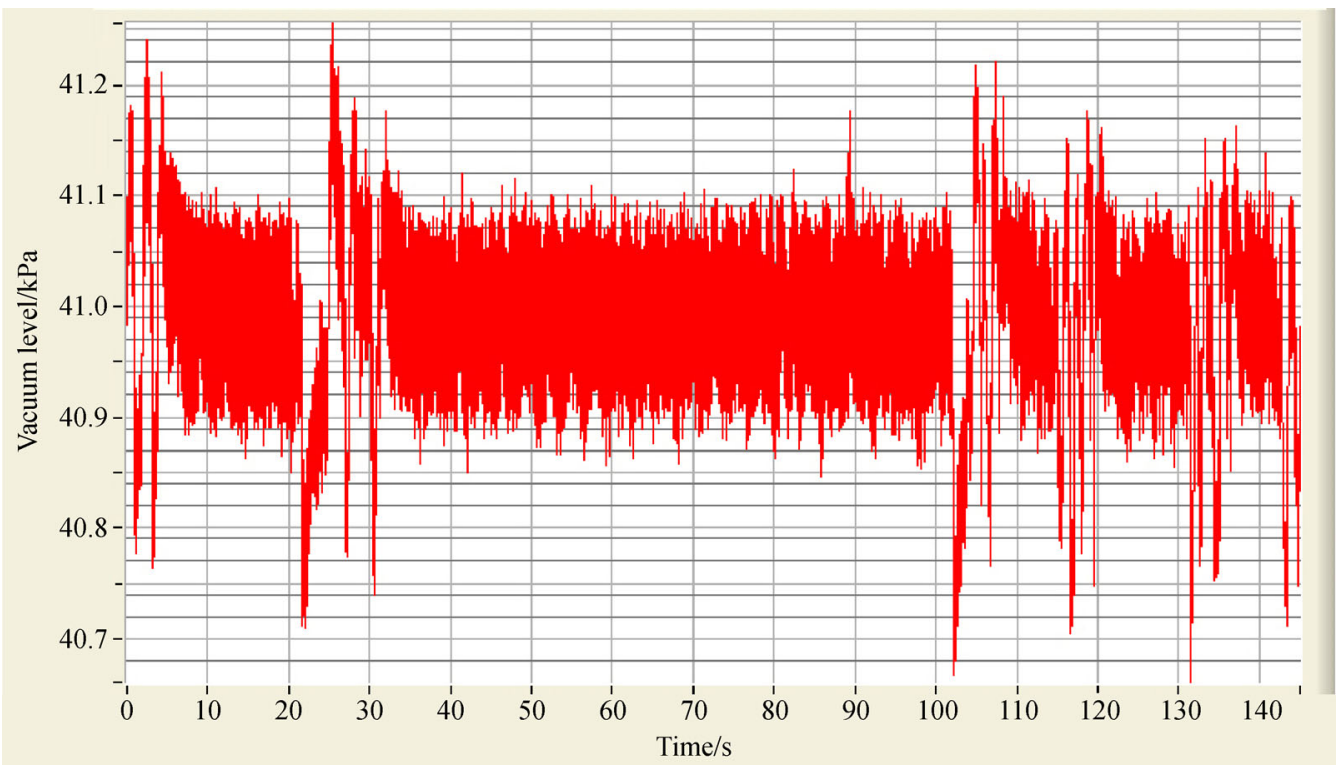

Fig. 2 Vacuum flow in the milkline during milking. From the analysis of the diagram it is possible to determine the mean value of the fluctuations and to evaluate the progress of the milking. 
Table 3 Mean vacuum level fluctuations $(\mathrm{kPa})$ in milklines of each milking parlor used in the study

\begin{tabular}{|c|c|c|c|c|c|}
\hline \multicolumn{2}{|c|}{ Farm A } & \multicolumn{2}{|c|}{ Farm B } & \multicolumn{2}{|c|}{ Farm C } \\
\hline Sensor 1 & Sensor 2 & Sensor 1 & Sensor 2 & Sensor 1 & Sensor 2 \\
\hline 0.8 & 0.8 & 0.4 & 0.4 & 0.3 & 0.4 \\
\hline
\end{tabular}

Note: Sensor 1, CF milkline; Sensor 2, DF milkline.

and the annual milk production. This allowed for comparisons of costs between farms. For the purchase and installation of the AfiMilk MCS system, a total of 68808 EUR was spent by Farm A, 134322 EUR by Farm B, and 83619 EUR by Farm C (Table 4).

The new implementation included two cooling tanks for milk separation on site. For this reason, a second cooling tank, with a capacity of $5000 \mathrm{~L}$ and a cost of 25212 EUR was purchased by each farm. The installation of the AfiMilk MCS system entailed minor building and electrical works with an average cost per farm of 1933 EUR for structural work and about 3000 EUR for electrical work. Dividing the total cost incurred by the number of raised cows, the average cost per head was 236 EUR. The average total cost per milking stall was about 5999 EUR, and this ranged from 5478 EUR for Farm B to 6268 for Farm C.

\section{Conclusions}

The AfiMilk MCS system allowed for separation of milk with high fat and protein concentration. The milk separation tests conducted on three dairy farms indicated that the separated milk had high coagulation properties compared to the bulk milk with increased fat of $18 \%-43 \%$ and protein of 3\%-7\%. The implementation of the AfiMilk MCS system in established milking parlors did not adversely affect the performance of the mechanical milking. Therefore, over a period of years a farm could improve its technological level with relatively minor structural and mechanical investments. The innovative systems installed in the milking parlors also allowed farmers to make more informed decisions for improving herd management. Specifically, the data regarding the individual somatic cell counts enabled cows with mammary gland infections to be promptly identified and monitored. This will help to reduce the number of cows which may be removed for sanitary issues. Furthermore, individual milk yield records represent important data to support decision making, such as for breeding programs, nutrition and animal welfare.

Dairy farms which adopt smart technologies may increase their competitiveness in the market and diversify the products they sell. The evaluation of the systems in this study has provided valuable data on reliability and efficiency of real-time milk separation and demonstrated that the system can be affordably implemented. Future research could explore new opportunities for milk separation, such as separating milk with different levels of nutraceutical components.

Acknowledgements The authors are grateful to the farmers that collaborated in the study, and to the dairy plant cooperative and their team who kindly collected and provided farm data. This work was supported by the Rural Development Program (Sardegna) 2007/2013, MEASURE 124, cooperation for the development of new products, processes and technologies in the agricultural and food sectors, as well as in the forest sector. Project Innovalatte Arborea.

Compliance with ethics guidelines Maria Caria, Giuseppe Todde, and Antonio Pazzona declare that they have no conflicts of interest or financial conflicts to disclose.

All applicable institutional and national guidelines for the care and use of animals were followed.

\section{References}

1. Fariña S R, Alford A, Garcia S C, Fulkerson W J. An integrated assessment of business risk for pasture-based dairy farm systems intensification. Agricultural Systems, 2013, 115: 10-20

2. Frick F, Sauer J. Deregulation and productivity: empirical evidence on dairy production. American Journal of Agricultural Economics, 2018, 100(1): 354-378

3. Todde G, Murgia L, Caria M, Pazzona A. Dairy energy prediction (DEP) model: a tool for predicting energy use and related emissions and costs in dairy farms. Computers and Electronics in Agriculture, 2017, 135: 216-221

4. Todde G, Murgia L, Caria M, Pazzona A. A Comprehensive energy analysis and related carbon footprint of dairy farms, Part 2: investigation and modeling of indirect energy requirements. Energies, 2018, 11(2): 463

5. Neethirajan S, Tuteja S K, Huang S T, Kelton D. Recent

Table 4 Summary of costs (EUR) for the installation of the AfiMilk MCS system, including construction and electrical work

\begin{tabular}{lccccccc}
\hline Farm & Construction works/EUR & $\begin{array}{c}\text { Electrical works/ } \\
\text { EUR }\end{array}$ & AfiMilk MCS/EUR & Milk tank/EUR & Total/EUR & $\begin{array}{c}\text { Average cost per Average cost per } \\
\text { head/EUR } \\
\text { milking stall/EUR }\end{array}$ \\
\hline A & 2000 & 4000 & 68800 & 25200 & 100000 & 200 & 6200 \\
B & 1800 & 3000 & 134300 & 25200 & 164300 & 274 & 5500 \\
C & 2000 & 2000 & 83600 & 25200 & 112800 & 235 & 6200 \\
\hline
\end{tabular}


advancement in biosensors technology for animal and livestock health management. Biosensors \& Bioelectronics, 2017, 98: 398407

6. Rutten C J, Steeneveld W, Oude Lansink A G J M, Hogeveen H. Delaying investments in sensor technology: the rationality of dairy farmers' investment decisions illustrated within the framework of real options theory. Journal of Dairy Science, 2018, 101(8): 76507660

7. Todde G, Murgia L, Caria M, Pazzona A. A multivariate statistical analysis approach to characterize mechanization, structural and energy profile in Italian dairy farms. Energy Reports, 2016, 2: 129134

8. Kaniyamattam K, De Vries A. Agreement between milk fat, protein, and lactose observations collected from the Dairy Herd Improvement Association (DHIA) and a real-time milk analyzer. Journal of Dairy Science, 2014, 97(5): 2896-2908

9. Gebbers R, Adamchuk V I. Precision agriculture and food security. Science, 2010, 327(5967): 828-831

10. Halachmi I, Guarino M. Precision livestock farming: a 'per animal' approach using advanced monitoring technologies. Animal, 2016, 10(9): 1482-1483

11. Quist M A, LeBlanc S J, Hand K J, Lazenby D, Miglior F, Kelton D F. Milking-to-milking variability for milk yield, fat and protein percentage, and somatic cell count. Journal of Dairy Science, 2008, 91(9): 3412-3423

12. Pavel E R, Gavan C. Seasonal and milking to milking variations in cow milk fat, protein, and somatic cell counts. Notulae Scientia Biologicae, 2011, 3(2): 20-23

13. Wedholm A, Larsen L B, Lindmark-Månsson H, Karlsson A H, Andrén A. Effect of protein composition on the cheese-making properties of milk from individual dairy cows. Journal of Dairy Science, 2006, 89(9): 3296-3305

14. De Marchi M, Bittante G, Dal Zotto R, Dalvit C, Cassandro M. Effect of Holstein Friesian and Brown Swiss breeds on quality of milk and cheese. Journal of Dairy Science, 2008, 91(10): 40924102

15. Manca M G, Serdino J, Gaspa G, Urgeghe P, Ibba I, Contu M, Fresi P, Macciotta N P P. Derivation of multivariate indices of milk composition, coagulation properties, and individual cheese yield in dairy sheep. Journal of Dairy Science, 2016, 99(6): 4547-4557

16. Weller J I, Ezra E. Genetic and phenotypic analysis of daily Israeli Holstein milk, fat, and protein production as determined by a realtime milk analyzer. Journal of Dairy Science, 2016, 99(12): 97829795

17. Auldist M J, Coats S, Rogers G L, McDowell G H. Changes in the composition of milk from healthy and mastitic dairy cows during the lactation cycle. Australian Journal of Experimental Agriculture, 1995, 35(4): 427-436

18. Svennersten-Sjaunja K, Sjaunja L O, Bertilsson J, Wiktorsson H. Use of regular milking records versus daily records for nutrition and other kinds of management. Livestock Production Science, 1997, 48 (3): $167-174$
19. Tao S, Bubolz J W, do Amaral B C, Thompson I M, Hayen M J, Johnson S E, Dahl G E. Effect of heat stress during the dry period on mammary gland development. Journal of Dairy Science, 2011, 94 (12): 5976-5986

20. Leitner G, Merin U, Lemberskiy-Kuzin L, Bezman D, Katz G. Realtime visual/near-infrared analysis of milk-clotting parameters for industrial applications. Animal, 2012, 6(7): 1170-1177

21. Leitner G, Merin U, Jacoby S, Bezman D, Lemberskiy-Kuzin L, Katz G. Real-time evaluation of milk quality as reflected by clotting parameters of individual cow's milk during the milking session, between day-to-day and during lactation. Animal, 2013, 7(9): 15511558

22. Leitner G, Lavi Y, Merin U, Lemberskiy-Kuzin L, Katz G. Online evaluation of milk quality according to coagulation properties for its optimal distribution for industrial applications. Journal of Dairy Science, 2011, 94(6): 2923-2932

23. Todde G, Caria M, Gambella F, Pazzona A. Energy and carbon impact of precision livestock farming technologies implementation in the milk chain: from dairy farm to cheese factory. Agriculture, 2017, 7(10): 1-11

24. Caria M, Todde G, Pazzona A. Modeling the collection and delivery of sheep milk: a tool to optimize the logistics costs of cheese factories. Agriculture, 2018, 8(5): 1-11

25. Singh S P, Ghosh S, Lakhani G P, Jain A, Roy B. Precision dairy farming: the next dairy marvel. Journal of Veterinary Science \& Technology, 2014, 5(2): 164

26. Werkheiser I. Precision livestock farming and farmers' duties to livestock. Journal of Agricultural \& Environmental Ethics, 2018, 31 (2): 181-195

27. Tullo E, Finzi A, Guarino M. Environmental impact of livestock farming and Precision Livestock Farming as a mitigation strategy. Science of the Total Environment, 2019, 650(Pt 2): 2751-2760

28. Associazione Regionale Allevatori Sardegna (ARAS). Laboratorio Analisi. Available at ARAS Website on October 1, 2018

29. Katz G, Merin U, Bezman D, Lavie S, Lemberskiy-Kuzin L, Leitner G. Real-time evaluation of individual cow milk for higher cheesemilk quality with increased cheese yield. Journal of Dairy Science, 2016, 99(6): 4178-4187

30. EC. Regulation (EC) No 853/2004 of the European Parliament and of the Council of 29 April 2004 laying down specific hygiene rules for on the hygiene of foodstuffs. Official Journal of the European Union, 2004: L139. 30.4.2004

31. Lombardo A, Boselli C, Amatiste S, Ninci S, Frazzoli C, Dragone R, De Rossi A, Grasso G, Mantovani A, Brajon G. From invention to innovation: risk analysis to integrate one health technology in the dairy farm. Frontiers in Public Health, 2017, 5: 302

32. ISO 5707:2007. Milking machine installations - Construction and performance

33. ISO 6690:2007. Milking machine installations-Mechanical tests

34. Mein G A. Basic mechanics and testing of milking systems. In: Bramley A J, Dodd F H, Mein G A, Bramley J A, editors. Machine Milking and Lactation. Huntingdon: Insight Books, 1992, 235-284 